\title{
Impact of positive images of a person with intellectual disability on attitudes: randomised controlled trial
}

\author{
Sabu John Varughese, ${ }^{1}$ Vania Mendes, ${ }^{2}$ Jason Luty ${ }^{3}$
}

The Psychiatrist (2011), 35, 404-408, doi: 10.1192/pb.bp.110.032425

${ }^{1}$ Community Drug and Alcohol Service, Thurrock; ${ }^{2}$ Institute of Psychiatry, London; ${ }^{3}$ South Essex Partnership NHS Trust, Southend on Sea and Cambridge \& Peterborough Mental Health NHS Trust, Cambridge

Correspondence to Jason Luty (jason.luty@yahoo.co.uk)

First received 24 Aug 2010, accepted 21 Apr 2011

\begin{abstract}
Aims and method Tackling discrimination, stigma and inequalities in mental health is a major UK government objective yet people with intellectual disability (also known as learning disability in UK health services) continue to suffer serious stigma and discrimination. We examine the effect of viewing pictures of a person with intellectual disability on stigmatised attitudes. The 20-point Attitude to Mental Illness Questionnaire (AMIQ) was used to assess stigmatised attitudes. Members of the general public were randomised to complete the questionnaire having looked at a good (attractive) or bad (unattractive) photograph of a person with intellectual disability.
\end{abstract}

Results Questionnaires were received from 187 participants (response rate 74\%). The mean AMIQ stigma score for the bad photo group was 1.3 (s.e. $=0.3$, median 1, interquartile range $(I Q R)=0-3, n=82)$. The mean AMIQ score for the good photo group was 2.8 (s.e. $=0.3$, median $3, \mathrm{IQR}=1-5, n=105$ ). The difference in AMIQ stigma score was highly significant (two-sided $P=0.0001$, median difference 2 , Mann-Whitney U-test).

Clinical implications Looking at a good (attractive) picture of a person with intellectual disability significantly reduces reported stigmatised attitudes, whereas a bad (unattractive) picture has no effect.

Declaration of interest None.
Tackling stigma and inequalities in health is a major UK government objective. ${ }^{1,2}$ Stigma is a social construction that devalues people because of a distinguishing characteristic or mark. ${ }^{3}$ The World Health Organization (WHO) and World Psychiatric Association (WPA) recognise that the stigma attached to mental disorders is strongly associated with suffering, disability and poverty. ${ }^{4}$ Stigma is also a major barrier to treatment-seeking behaviour. ${ }^{5}$ Many studies show that negative attitudes towards the mentally ill are widespread. ${ }^{6}$ Furthermore, the media generally depicts people who are mentally ill as violent, erratic and dangerous. ${ }^{7}$ There have been several attempts to reduce the stigma of mental illness including the UK Royal College of Psychiatrists' 'Changing Minds' campaign, ${ }^{8}$ the current 'See me' campaign in Scotland (www.seemescotland.org.uk) and 'Time to Change' campaign in England (www.time-tochange.org.uk).

Society's neglect and ill treatment of people with intellectual disability (also known as learning disability in UK health services) is infamous. ${ }^{9,10}$ Various organisations report that people with intellectual disability encounter stigma, prejudice and suffer continued denial of their human rights. ${ }^{11,12}$ However, very little research is published on the stigma of intellectual disability, although a recent paper describes a new instrument for measuring the stigma experienced by people with intellectual disability and describes the current situation. ${ }^{13}$ However, the proportion of research reports on intellectual disability was consistently less than any other diagnostic category in a survey of five high impact psychiatric journals. ${ }^{14}$ In a Mencap survey of 5000 people with intellectual disability, over $80 \%$ had been bullied in the previous year, a third on a weekly basis, a half reported verbal abuse and a quarter reported physical assaults. ${ }^{15}$ People with intellectual disability were twice as likely to be victims of crime. ${ }^{16}$ Inequalities in healthcare were identified by an investigation conducted by the Disability Rights Commission in the UK and Mencap's Death by Indifference report. ${ }^{11}$ The UK Government report, Valuing People, aims to counter these problems and improve the lives of people with intellectual disability by ensuring that services respect their rights, choices, independence and social inclusion, and ensuring their access to mainstream services. ${ }^{17}$

There is a view that a disfigured or 'dysmorphic' facial appearance may further stigmatise people. ${ }^{18-20}$ By comparison, marketing strategies for commercial products 
invariably associate their product with positive images and avoid associating it with any negative images. ${ }^{21-27}$ Hence our study looked at the effect of viewing pictures of people with intellectual disability and dysmorphic facial features on stigmatised attitudes.

\section{Method \\ Participants}

We recruited 250 participants from the UK general population using direct mail shots and advertisements in local newspapers as described in a previous study. ${ }^{28} \mathrm{~A}$ total of 125 participants per group were approached with the aim of generating approximately 100 responses per group.

\section{Instruments}

The 5-item Attitude to Mental Illness Questionnaire (AMIQ) is a brief, self-completion questionnaire. ${ }^{28,29}$ Respondents read a short vignette describing an imaginary patient and answered five questions (Appendix). Individual questions were scored on a 5-point Likert scale (maximum +2 , minimum -2) with blank questions, 'neutral' and 'don't know' scored zero. The total score for each vignette ranged between -10 and +10 . The AMIQ has been shown to have good psychometric properties in a sample of over 800 members of the UK general public (one component accounted for $80.2 \%$ of the variance; test-retest reliability was 0.702 (Pearson's correlation coefficient); alternate testreliability $v$. Corrigan's attribution questionnaire was 0.704 (Spearman's rank correlation Rho); Cronbach's alpha was 0.93). ${ }^{28}$ Other research we have undertaken has shown a 2-unit difference between the stigma scores of pharmacists who were prepared to dispense methadone to people dependent on opiates and pharmacies who did not ${ }^{30}-$ the positive predictive value was $77 \%$ using a cut-off AMIQ score of 0 . Hence the AMIQ scores are able to predict discrimination by people towards those with mental illness in a real-world situation.

\section{Procedure}

Participants were randomised using the randomisation function of the Stats Direct statistical package (version 2.4) for Windows. The 'bad photo' group were asked to look at a photograph of a man with intellectual disability from the cover of the Learning Disability Coalition leaflet entitled Tell it Like it is. ${ }^{31}$ The photo shows the face of a man with dysmorphic features, a partial ptosis of one eye and a mild skin condition visible on his face and chin, wearing a casual outfit. Participants were then asked to complete the AMIQ stigma questionnaire with the following description: 'Oliver has Down's syndrome. He is 32 years old and lives with his parents. He cannot read or write but he is happy and cheerful and keen to help people' (Appendix). The 'good photo' group were asked to look at a photo of a man with intellectual disability who was smartly dressed in a shirt and tie apparently at work in an office (see August 2010 issue of The Psychiatrist). Participants were then asked to complete the AMIQ stigma questionnaire.

\section{Data analysis}

Randomisation, correlation coefficients and non-parametric (Mann-Whitney) tests were used to generate and compare differences in the two groups using the Stats Direct statistical software package (version 2.4) for Windows.

\section{Results}

Questionnaires were received from 187 participants (response rate $74 \%$ ). Both groups were closely comparable on demographic data. For the bad photo group $(n=82)$, the mean age was 51 years (s.e. $=1.8$ ), $46 \%$ were male and $59 \%$ in paid employment. For the good photo group $(n=105)$, the mean age was 54 years (s.e. $=1.5$ ), $40 \%$ were male and $56 \%$ in paid employment. Over $90 \%$ of both groups described their ethnic group as White British.

The mean AMIQ stigma score for the bad photo group was 1.3 (s.e. $=0.3$, median 1 , interquartile range $(\mathrm{IQR})=0-3$, $n=82$ ). The mean AMIQ score for the good photo group was 2.8 (s.e. $=0.3$, median $3, \mathrm{IQR}=1-5, n=105$ ). The difference in AMIQ stigma score was highly significant (two-sided $P=0.0001$, median difference 2; Mann-Whitney $U$-test).

\section{Discussion}

This study shows that an attractive photograph of a person with intellectual disability significantly reduces stigmatised attitudes when compared with an unattractive photograph. Validation of the AMIQ shows that in practice the range of scores varied from -5 to +5 . Furthermore, other research by our group has shown a 2-unit difference between the stigma scores of pharmacists who were prepared to dispense methadone to people dependent on opiates and pharmacies who did not. ${ }^{30}$ Hence the median difference ( 2 units) is likely to be worthwhile in practice.

In another study we found that a good (attractive) photo produced a mean AMIQ score of 2.43 (s.e. $=0.12$, $n=174){ }^{32}$ This is closely comparable with the good photo group in the current report (mean AMIQ score 2.8). A control group that had no photo attached produced an AMIQ score of 1.56 (s.e. $=0.21, n=186$ ). This is closely comparable to the bad photo result from the current report (mean AMIQ score 1.3). This suggests that a bad photo is better than no photo at all, whereas an attractive photo produces a highly significantly positive response.

Stigmatised attitudes are widely reported towards people as a result of disfigurement or dysmorphic facial appearance. ${ }^{18-20}$ By contrast, presenting individuals in a positive manner can significantly reduce the stigma of alcoholism, although the effect found for schizophrenia was negligible. $^{33,34}$ Looking at an attractive picture of a man with Down syndrome actually reduced stigmatised attitudes and this is supported by most marketing strategies that invariably recommend associating a product with a successful, physically attractive individual rather than an unappealing image. ${ }^{21-27}$

\section{Methods to reduce the stigma of mental illness}

The Royal College of Psychiatrists' 'Changing Minds' campaign aimed to promote positive images of mental illness, challenge misrepresentations and discrimination 
and educate the public to the real nature and treatability of mental disorder. ${ }^{6}$ Crisp et al's large survey showed that people with substance use disorders were the most stigmatised of all those with mental disorder. ${ }^{6}$ More recently, national anti-stigma campaigns have been launched in Scotland ('See me') and England ('Time to Change'), although unfortunately there have been reports that national anti-stigma campaigns are not particularly effective. ${ }^{14,35,36}$ These reports discuss the disappointing results to date from the 'Defeat Depression', the 'Changing Minds' and the Scottish 'See me' campaign. Although a significant amount of work has been undertaken on the stigmatising effect of a diagnosis of schizophrenia, very little research has looked at the stigmatised attitudes directed against people with intellectual disability.,10,14,37 For example, the stigma of intellectual disability is not addressed by either the 'Changing Minds' or 'Time to Change' campaigns or the UK government publication Action on Mental Health. ${ }^{1}$ Methods of dealing with stigma are not addressed in the UK Department of Health report, Valuing People, which specifically concerns people with intellectual disability. ${ }^{17}$

Action on Mental Health ${ }^{1}$ provides 12 individual fact sheets to reduce stigma. This supplements the efforts of the 'Changing Minds' campaign. Both give practical advice to health agencies, employers and stakeholders to tackle stigma. Providing factual information in brief fact sheets $^{38,39}$ or through extensive interventions such as educational courses has been reported to reduce stigma. ${ }^{34,40-42}$ Unfortunately, responses tend to be small, especially if negative consequences of mental illness are also disseminated. Knox et al showed that addressing stigmatised attitudes to mental illness among four million members of the US armed forces with mandatory training to recognise and treat mental illness significantly reduced suicide rates but not stigmatised attitudes. ${ }^{42}$ Pinfold et al reported a project in which 472 English secondary school children attended mental health awareness workshops. ${ }^{43}$ Overall, there was a small but positive shift in their understanding of mental illness. However, it was possible to argue that in both these settings participants engaged in anti-stigma training, whereas any involvement by the general public is entirely voluntary.

Penn et al reported a study of 163 US undergraduates who were assigned randomly to four groups: three watched a documentary about schizophrenia (represented realistically), polar bears or being overweight, and the fourth group was a 'no video' control group. ${ }^{44}$ The schizophrenia documentary did not change attitudes. Depicting the negative consequences of schizophrenia may be realistic but may not be the best way to reduce stigma. Depicting a success story may be more effective, although viewers may then classify this as an exception to the rule. ${ }^{34}$ By contrast another study showed that presenting individuals who had recovered from alcoholism in a positive manner can significantly reduce the stigma of alcoholism, however the effects for schizophrenia were negligible. ${ }^{33}$ Luty et al also found that a brief face-to-face intervention (motivational interviewing) helped to reduce the stigma of alcoholism, although the effect was modest. ${ }^{45}$
Promoting direct interpersonal contact with people who are mentally ill may be an effective strategy, but the amount of contact required has not been established. ${ }^{34,38,43,46}$ It would be difficult, in practice, to ensure that a significant proportion of the public had contact with people with a severe mental illness. Our report indicates that looking at pictures of people with intellectual disability and dysmorphic facial features reduces stigmatised attitudes significantly and this may act as an effective substitute for direct contact.

\section{Strengths and limitations}

The AMIQ was used in this project as it is convenient and has been well validated. ${ }^{28,29,33}$ Other instruments are available, although these tend to be much longer, involve interviews or tend to address the experience of stigma by people with mental illness (e.g. the Internalised Stigma of Mental Illness scale $\left.{ }^{47}\right) .^{28}$

Although there was an excess of female respondents, the age and employment status of participants were reasonably matched to that from UK census surveys. Hence the sample appears to be a reasonable cross-section of the British public. However, it is self-selecting and may not generalise across the whole population. Ideally, interviews could be conducted using a quota survey of households with repeat visits for non-responders. ${ }^{6}$ Unfortunately this is prohibitively expensive.

The study presented a hypothetical person with intellectual disability, as, it was not possible to measure stigmatised behaviour towards real people with intellectual disability. Moreover, the written views and expressed attitudes may not translate into any enduring behavioural change. Although there was no direct contact between participants and researchers, participants are likely to make some assumptions about the potentially liberal beliefs of researchers. Hence social desirability bias may affect the results. However, the results from other similar studies demonstrated a negative view of people with active substance use disorder and suggest that participants had little reservation about indicating their disapproval of these disorders. ${ }^{28,33}$ This is confirmed in other reports. ${ }^{6}$ This would indicate that social disability bias had only a modest effect. Furthermore, social desirability bias would affect both groups equally.

\section{Funding}

The research was supported by Southend MIND.

\section{About the authors}

Dr Sabu John Varughese (MBBS) is a staff grade psychiatrist (specialty doctor) at the Community Drug and Alcohol Service, Thurrock. Vania Mendes (BSC) is a student psychologist at the Institute of Psychiatry, London. Dr Jason Luty (PhD, MRCPsych) is a Consultant in Addictions Psychiatry at the South Essex Partnership NHS Trust, Southend on Sea and an Honorary Consultant in Addictions Psychiatry at the Cambridge \& Peterborough Mental Health NHS Trust, Cambridge. 


\section{Appendix}

\section{Attitude to Mental Illness Questionnaire (AMIQ) ${ }^{28,29}$}

Participants were presented with either photo A (good photo) or photo B (bad photo).

This is a fictitious report. This is Oliver.

'Oliver has Down's syndrome. He is 32 years old and lives with his parents. He cannot read or write but he is happy and cheerful and keen to help people'. Please underline the answer which best reflects your views:

Do you think that this would damage Oliver's career? Strongly agree $^{-2} /$ Agree $^{-1} /$ Neutral $^{0} /$ Disagree $^{+1} /$ Strongly disagree $^{+2} /$ Don't know $^{0}$

I would be comfortable if Oliver was my colleague at work? Strongly agree $^{+2} /$ Agree $^{+1} / \mathrm{Neutral}^{\mathrm{O}} /$ Disagree $^{-1} /$ Strongly disagree $^{-2} /$ Don't know ${ }^{0}$

I would be comfortable about inviting Oliver to a dinner party?

Strongly agree ${ }^{+2} /$ Agree $^{+1} /$ Neutral $^{0} /$ Disagree $^{-1} /$ Strongly disagree $^{-2} /$ Don't know ${ }^{0}$

How likely do you think it would be for Oliver's wife to leave him?

Very likely $^{-2} /$ Quite likely $^{-1} / \mathrm{Neutral}^{0} /$ Unlikely $^{+1} /$ Very unlikely $^{+2} /$ Don't know ${ }^{0}$

How likely do you think it would be for Oliver to get in trouble with the law?

Very likely $^{-2} /$ Quite likely $^{-1} /$ Neutral $^{0} /$ Unlikely $^{+1} /$ Very unlikely $^{+2}$ / Don’t know ${ }^{0}$

\section{References}

1 Office of the Deputy Prime Minister. Action on Mental Health - A Guide to Promoting Social Inclusion. Office of the Deputy Prime Minister, 2004.

2 Darzi A. Our NHS, Our Future. NHS Next Stage Review: Interim Report Department of Health, 2007.

3 Biernat M, Dovidio JF. Stigma and stereotypes. In The Social Psychology of Stigma (eds TF Heatherton, RE Kleck, MR Hebl): 88-125. Guilford Press, 2000

4 Corrigan P, Markowitz FE, Watson A, Rowan D, Kubiak MA. An attribution model of public discrimination towards people with mental illness. J Health Soc Behav 2003; 44: 162-79.

5 Appleby L. Safer Services. Department of Health, 1999.

6 Crisp AH, Gelder M, Goddard E, Meltzer H. Stigmatization of people with mental illness: a follow-up study within the Changing Minds campaign of the Royal College of Psychiatrists. World Psychiatry 2005; 4: $106-13$

7 Granello D, Pauley PS, Carmichael A. Relationship of the media to attitudes towards people with mental illness. J Humanist Couns Educ Dev 1999; 38: 89-110.

8 Royal College of Psychiatrists. Changing Minds: History of the Campaign Royal College of Psychiatrists, 2009 (http://www.rcpsych.ac.uk/ campaigns/changingminds/whatischangingminds/whychangingminds. aspx).

9 Sperlinger A Introduction. In Adults with Learning Disabilities: A Practical Approach for Health Professionals (eds J O'Hara \& A Sperlinger): 139-53. John Wiley \& Sons, 1997
10 O'Hara J. Learning disabilities and ethnicity: achieving cultural competence. Adv Psychiatr Treat 2003; 9: 166-74.

11 Mencap. Death by Indifference. Mencap, 2007.

12 European Union Monitoring and Advocacy Programme. Report on People with Intellectual Disabilities. Open Society Institute, 2004.

13 Ali A, Strydom A, Hassiotis A, Williams R, King M. A measure of perceived stigma in people with intellectual disability. $\mathrm{Br} J$ Psychiatry 2008; 193: 410-5.

14 Luty J, Umoh O, Sessay M, Sarkhel A. Effectiveness of Changing Minds campaign factsheets in reducing stigmatised attitudes towards mental illness. Psychiatr Bull 2007; 31: 377-81.

15 Mencap. The Need to Combat Bullying of People with a Learning Disability. Mencap, 2000

16 Mencap. Barriers to Justice. Mencap, 1997.

17 Department of Health. Valuing People: A New Strategy for People with Learning Disability for the 21st Century. Department of Health, 2001.

18 Houston V, Bull R. Do people avoid sitting next to someone who is facially disfigured? Eur J Soc Psychol 1994; 24: 279-84.

19 Strauss RP, Ramsey BL, Edwards TC, Topolski TD, Kapp-Simon KA Thomas CR, et al. Stigma experiences in youth with facial differences: a multi-site study of adolescents and their mothers. Orthod Craniofac Res 2007; 10: 96-103.

20 Kaney S. Overcoming the stigma of disfigurement. In Stigma and Social Exclusion in Healthcare (eds T Mason, C Carlisle, C Watkins \& E Whitehead): 142. Routledge, 2001

21 Atkinson RL, Atkinson RC, Smith EE, Bem DJ, Nolen-Hoeksema S Hilgard's Introduction to Psychology (12th edn). Harcourt Brace, 1996.

22 McGrouther DA. Facial disfigurement. The last bastion of discrimination. BMJ 1997; 314: 991.

23 Till BD, Busler M. Matching products with endorsers: attractiveness versus expertise. J Consum Mark 1998; 15: 576-86.

24 Wilmshurst J, Mackay A. The Fundamentals and Practice of Marketing (4th edn). Butterworth, 2002.

25 Kahle LR, Kim C. Creating Images and the Psychology of Marketing Communication: 163. Psychology Press, 2006.

26 Patzer GL. The Power and Paradox of Physical Attractiveness. Universal Publishers, 2007.

27 Lin $\mathrm{CL}$, Yeh JT. Comparing society's awareness of women: mediaportrayed idealized images and physical attractiveness. J Bus Ethics 2009; 90: 61-79.

28 Luty J, Fakuda D, Umoh O, Gallagher J. Validation of a short instrument to measure stigmatised attitudes towards mental illness. Psychiatr Bull 2006; 30: 257-60.

29 Cunningham JA, Sobell LC, Chow VMC. What's in a label? The effects of substance types and labels on treatment considerations and stigma. J Stud Alcohol 1993; 54: 693-9.

30 Luty JS, Kumar P, Stagias K. Stigmatised attitudes in independent pharmacies associated with discrimination towards individuals with opioid dependence. Psychiatrist 2010; 34: 511-4

31 Learning Disability Coalition. Tell it Like it is. Learning Disability Coalition, 2009 (http://www.learningdisabilitycoalition.org.uk/download/Tell_it like_it_is.pdf).

32 Varughese SJ, Luty J. Stigmatised attitudes towards intellectua disability: a randomised crossover trial. Psychiatrist 2010; 34: 318-22.

33 Luty J, Rao H, Arokiadass SMR, Easow JM, Sarkhel A. The repentant sinner: methods to reduce stigmatised attitudes towards mental illness. Psychiatr Bull 2008; 32: 327-32.

34 Corrigan PW, Penn DL. Lessons from social psychology on discrediting psychiatric stigma. Am Psychol 1999; 54: 765-76.

35 Paykel ES, Hart D, Priest RG. Changes in public attitudes to depression during the Defeat Depression Campaign. Br J Psychiatry 1998; 173: 519-22.

36 Mehta N, Kassam A, Leese M, Butler G, Thornicroft G. Public attitudes towards people with mental illness in England and Scotland, 19942003. Br J Psychiatry 2009; 194: 278-84 
37 Penn DL, Kommana S, Mansfield M, Link BG. Dispelling the stigma of schizophrenia. Schizophr Bull 1999; 25: 437-46.

38 Penn DL, Guynan K, Daily T, Spaulding WD, Garbin P, Sullivan M Dispelling the stigma of schizophrenia. Schizophr Bull 1994; 20: 567-77.

39 Thornton JA, Wahl OF. Impact of newspaper articles on attitudes towards mental illness. J Community Psychol 1996; 24: 17-23.

40 Mayville E, Penn DL. Changing societal attitudes towards persons with severe mental illness. Cogn Behav Pract 1998; 5: 241-53.

41 Penn DL, Martin J. The stigma of severe mental illness. Some potential solutions for a recalcitrant problem. Psychiatr Q 1998; 69: 235-47.

42 Knox T, Smith J, Hereby H. Risk of suicide and related adverse outcomes after exposure to a suicide prevention programme in the US air force: cohort study. BMJ 2003; 327; 1376-8.
43 Pinfold V, Toulmin H, Thornicroft G, Farmer P, Huxley P, Graham T. Reducing psychiatric stigma and discrimination: evaluation of educational interventions in UK secondary schools. $\mathrm{Br} J$ Psychiatry 2003; 182: 342-6

44 Penn DL, Chamberlin C, Mueser KT. The effects of a documentary film about schizophrenia on psychiatric stigma. Schizophr Bull 2003; 29: 383-91.

45 Luty J, Umoh O, Nuamah F. Effect of brief motivational interviewing on stigmatised attitudes towards mental illness. Psychiatr Bull 2009; 33 212-4.

46 Wolff G, Pathare S, Craig T, Leff J. Public education for community care. A new approach. Br J Psychiatry 1996; 168: 441-7.

47 Ritsher JB, Otilingam PG, Grajales M. Internalized stigma of mental illness: psychometric properties of a new measure. Psychiatry Res 2003; 121: 31 .

\title{
Shame and acute psychiatric in-patient care
}

\author{
David Richard Crossley, Alun Charles Jones ${ }^{1,2}$
}

The Psychiatrist (2011), 35, 408-412, doi: 10.1192/pb.bp.110.031666

${ }^{1}$ Betsi Cadwaladr University Health Board, Wrexham; ${ }^{2}$ University of Chester, Chester

Correspondence to David Richard Crossley

(david.crossley@wales.nhs.uk)

First received 28 Jun 2010, final revision 7 Mar 2011, accepted 25 May 2011
Aims and method To investigate the complementarities of staff and service users' experiences of shame in psychiatric in-patient settings. Qualitative methods were used by means of focus group interviews in two compositions - staff and service users. Data were transcribed and thematically analysed.

Results Service user group transcripts revealed four prominent themes: 'loss of value', 'loss of adulthood and autonomy', 'loss of subjectivity' and 'shaming or blaming of others'. Staff group transcripts also revealed two themes one of which overlapped with service users ('shaming or blaming of others') and one of which was distinct ('entrapment').

Clinical implications Shame processes may be elicited by caregiving and impede treatment. Staff find themselves in the predicament of provoking the problems they intend to address. Suggestions are made as to how to respond to this dilemma and practically improve aspects of the in-patient care process to reduce shame.

Declaration of interest None.
Concerns about stigma and the quality of psychiatric in-patient care are gaining international prominence on mental health agendas, yet comparatively less attention has been given to the related experience of shame. Stigma has been defined as a deep shame-provoking mark or flaw linked to being a member of a group that is devalued by society. ${ }^{1}$ Although shame may have social origins and repercussions, it characteristically involves global evaluations about the self as unattractive and undesirable - to use Gilbert's phrase 'being in the world as a self one does not wish to be'. ${ }^{2}$ As a result shame can correlate with a wide range of psychopathology and self-esteem measures. ${ }^{3-5}$ In 1987 Lazare noted that people receiving treatment and healthcare sometimes fail to adhere to treatment or else neglect consultations because of shame. ${ }^{6}$ Compared with other in-patient settings, psychiatric in-patients may not receive comparable levels of support from relatives.? Individuals may enter hospital vulnerable to feeling shame, influencing subsequent treatment and care processes. ${ }^{6}$ To date, there are no published reports specifically addressing the global in-patient experience of shame comparing service users' and professionals' perspectives. ${ }^{8}$ The aim of this qualitative research was to understand ways in which shame experiences are brought into, elicited by and dealt with in in-patient psychiatric care.

\section{Method}

Data were gathered using a focus group design. Focus groups are considered effective in gathering information 